\title{
Psychiatry and neuropathology: the maturing of a relationship
}

\author{
W A Lishman
}

I am grateful for the invitation to deliver this third David Oppenheimer lecture. It presents an opportunity to explore the relationships between the disciplines of psychiatry and neuropathology, and also of course to consider neurology, which is closely related to both.

And I am pleased that the lecture is in honour of the memory of David Oppenheimer, who introduced me to the mysteries of neuropathology when I worked in neurology in Oxford some 35 years ago. Later at the Maudsley Hospital and Institute of Psychiatry I met Peter Daniels and Sabina Strich, David's predecessors at Oxford. The Maudsley Hospital had valued neuropathology from the time it was founded.

This brings us to the central theme of my talk, and the conundrum with which psychiatry has wrestled for the past two centuries or more-the complex, tantalising, relationship between disorders of the mind and identifiable disorder of the brain, in effect the relationship between psychiatry and neuropathology.

\section{Historical development}

Some regard history as a rather sterile exercise where science is concerned. But without a glance at the past it is hard to appreciate the richness of the present day scene. It may therefore be useful to sketch in something of the evolution of the current status quo.

We start with a remarkable man who was not involved with medicine himself-Francis Bacon, philosopher and Lord Chancellor of England. What he wrote about mental disorders in $1605^{1}$ is more astonishing each time we read it. In effect he set out detailed prescriptions for research which were to unfold slowly over the next 350 years. He recommended four lines of enquiry, each of which has borne fruit in different ways: the first, to consider "the Seates, and Domiciles which the severall faculties of the minde doe take and occupate in the Organs of the bodie" began with phrenology some 200 years later, and has continued as the cornerstone of research in neuropsychology.

His second "to set downe a Narrative of the speciall cases of his patientes, and how they proceeded" forms the basis of psychiatric nosology, which reached its height with the work of Kraepelin at the turn of the present century.

The third is "inquirie which is made by Anatomie.... And as for the footesteps of diseases, and their devastations of the inward parts... they ought to have beene exactly observed by multitude of Anatomies." Bacon, is referring, of course, to the need for clinicopathological correlations-one of the main spurs to neurology's progress but, as we shall see, a less straightforward issue for psychiatry.

The fourth area points directly towards what we would today call social psychiatry: "Humane Philosophy or Humanitie ... hath two parts. The one considereth Man segregate, or distributively: The other congregate or in societie".

It was almost a century after this was written that responsibility for the care of the insane passed finally into medical hands. Before this theologians and philosophers had had most to say about mental illness, and mystical conceptions had been dominantsome sufferers were esteemed and venerated, others persecuted as demoniacally possessed. The medical profession then began to hazard an interest. Its early formulations were often bizarre and naïve, sometimes focusing on the brain but just as often on the uterus or gastrointestinal tract. Psychological causes also came to be championed by way of disturbed emotions or "passions". In this manner the stage was set for the great divisions of opinion which have characterised psychiatry ever since. Psychiatry's muddles and uncertainties were still rife in the 19th century, when they stood in sharp contrast to the evolving discipline of neurology. Neurology and knowledge of the brain grew up hand in hand together. Each advance in the understanding of brain anatomy and physiology led to applications in the clinical field, with clinical observation feeding constantly back to refine understanding of the brain. And neurology's ally from the start was neuropathology. Abercrombie's work in $1828^{2}$ rested on clinicopathological correlations on a large series of carefully studied cases. Here was the start of a more rewarding set of enterprises than confronted those, such as John Haslam at Bethlem, who were looking to brain pathology for clarifying mental illness. The more that was learned about the nervous system, the more could neurological illnesses be explained. The 
closer neurological manifestations could be delineated, the greater the impetus for pathological examination of the brain after death.

Psychiatry watched from the sidelines and envied this success. But its attempts to follow suit were bedevilled by errors and false starts. One of the more remarkable was the upsurge of phrenology from the teaching of Gall and his disciples. Franz Joseph Gall was a talented neuroanatomist who made major discoveries for his time. But in addition he made farfetched claims which caught the public imagination. He insisted that the mind could be analysed into independent faculties, each with its seat in the cortex, and-the fatal flawthat the size of each "cerebral organ" matched its functional capacity and could be determined by inspecting the contours of the skull. Gall's system challenged the prevalent notion of holistic brain function and provided a powerful impetus to neurology, but when venturing into the psychological field it overreached and discredited itself.

Another reverse followed later in the century when Charcot began his studies of hysteria at the Salpêtrière. He developed theories of hysteria and of hypnotism which postulated disordered cerebral function. To Charcot the stages of hypnotism were the outward signs, reflecting physiological changes in the nervous system indicative of hysteria. A clash of opinion followed when Liébeault and Bernheim claimed the converse view-that psychological factors were responsible for the induction of hypnosis, and that the "aptitude to transform an idea into an act" was possessed, not by hysterics alone, but by everyone in varying degree. The second view of course prevailed. A psychological conception won over a physiological model of a complex mental phenomenon.

Throughout the 19th century, nevertheless, psychiatrists continued to look towards neuropathology. The main focus of activity passed to Germany, where psychiatrists of this period were almost without exception good neurologists and neuropathologists. The formidable figure of Wilhelm Griesinger in Berlin proclaimed that "mental diseases are brain diseases". Before his death in 1868 he had written: "Psychiatry and neuropathology are not merely two closely related fields; they are but one field in which only one language is spoken and the same laws rule."3 Heinroth, who held the Chair at Liepzig, was alarmed at so "somatic" a view-the richness of mental life was being viewed too narrowly: "Soul! The great most meaningful word! The only treasure of man, the very being of the self. How they drag you down by making you the slave of the body! Yes, they drag you down when they look upon you as a cadaver which one could cut to pieces with a knife, or as a chemical compound which could be broken down into elements, or as a mechanical contraption the workings of which one could calculate with mathematics."4

Griesinger's position was reinforced by the success achieved in relation to general pare- sis. Here was a conspicuous and common mental disorder with, at last, a firm pathological basis. Pick's and Alzheimer's diseases were to follow later under the influence of such an approach. But this left the great mass of other psychiatric illness-the major psychoses, the neuroses, and the personality disorders-still far removed from a neuropathological explanation.

And here it was that the pendulum took a massive swing. As a curious and fascinating consequence of the earlier debates between Charcot and Bernheim, dynamic psychiatry was born. The young Sigmund Freud visited both contestants and decided firmly in favour of psychological systems of explanation. He commenced his own studies of hysteria and developed his own astounding edifice of psychodynamic theory. A new model of the mind, no less, was born, with entirely new systems of explanation for mental illness. From that point onwards a dichotomy was established and was to become deeply entrenched. As we entered the 20th century, "mind science" was pitted against "brain science" as the way forward for clarifying mental derangement. The schism has plagued us (and in some ways benefited us) ever since.

\section{The schism}

I do want to emphasise that this division of opinion has had beneficial as well as adverse influences. It has broadened the outlook of psychiatry in very important ways. To have aped neurology too closely would have impeded progress disastrously. Psychiatry, by standing back from the brain and the neurosciences for a while, recruited to its ranks those who concentrated on other methods for understanding mental illness. Psychodynamics, although often claiming more than its just deserts, has enriched our knowledge enormously. Developments in clinical psychology, in particular learning theory, have brought new approaches to treatment in the fields of depression and the neuroses. And the study of social processes has been rewarding both in theory and in practice. "Mind science" has deserved and amply repaid its place in the armamentarium of psychiatry. To have pursued a headlong search for tissue pathology alone would have eclipsed much that is valuable, particularly in the treatment domain.

The downside of the situation has been the split that emerged between neurology and psychiatry. Instead of a close continuing dialogue, with mutual enrichment, during most of this century neurologists and psychiatrists have tended to drift apart. And neuropathologists, not surprisingly, have found their closest allegiance with neurology. There they have had a central role, an equal partnership in unravelling "the footesteps of diseases and their devastations of the inward parts". Neuropathology has often taken the lead in the demarcation of neurological disease entities, in refining their categories, and perform- 
ing the role of arbiter when diagnosis is in doubt.

Equally unsurprising has been neuropathology's disenchantment with psychiatry. It has often not known where to look for the supposed nugget of brain pathology; or it has suspected that the brain malfunction must be infinitely diffused. And apart from a handful of disorders inherited from the turn of the century it mostly looked in vain. It found psychiatric nosology in disarray. Amorphous and ill defined samples of patients usually yielded equally amorphous findings. The relationship between psychiatry and neuropathology has often tended to be one of frustration bordering on despair.

\section{Resurrection}

And yet, as with most relationships hope has sprung eternal. And throughout the present century there has been a periodic fanning of the flame.

First we return to general paralysis of the insane. Early in the century the syphilitic aetiology of general paresis was decisively proved when Noguchi and Moore demonstrated the Treponema pallidum within the brain in $1913 . .^{5}$ This ended disputes about the cause of the condition, which are nowadays hard to imagine. A relationship between syphilis and insanity had long been recognised, but until the organism itself was revealed in the brain aetiological importance continued to be given to hereditary factors, alcohol consumption, and even sexual excess.

In the wake of the first world war there was an explosive "experiment of nature" in the form of epidemics of encephalitis lethargica that swept across Europe. Attacks could be accompanied by marked psychiatric disturbances, clearly resulting from brain malfunction. Conditions resembling the catatonia of schizophrenia, or states of hallucinatory excitement and terror, could be observed from the outset. Among the long term sequelae were numerous phenomena which had previously been explained in "functional" terms-tics, torticollis, compulsions, profound disturbances of will, and far reaching changes of personality.

Thus a great variety of psychopathological phenomena could be ascribed to pathological changes in the brain, and this focused attention on the relationship between mental symptoms and brain structure as never before. Von Economo wrote in 1929: “just as we find it hard today to follow up the trend of thought of our scientific predecessors for whom bacteriology and the lore of brainlocalisation did not exist, future generations will hardly be able to appreciate our preencephalitic neurological and psychiatric conceptions, particularly with regard to socalled functional disturbances." 6 Unfortunately, however, as encephalitis died away, so in large measure did the lessons to be learned from it.

Another pointer to the promise of neuropathology came from experimental brain research. During the middle part of the century this came to illuminate behaviour. An enlarging body of evidence pointed to systems of the brain which dealt with the ground stuff of psychiatry-with the regulation of higher order functions and of emotion. Just as discoveries in the previous century had been of benefit to neurology, so now it was found that discrete brain lesions could affect the control of aggression and other complex behaviours.

Lesions in the hypothalamus and temporal lobe were found to alter fear and aggression. ${ }^{78}$ Cingulectomy in monkeys led to inquisitiveness, loss of shyness for humans, and loss of "social conscience" in interaction with other monkeys. ${ }^{910}$ Olds and Milner ${ }^{11}$ demonstrated centres governing reward and aversion in the hypothalamus and rhinencephalon. On stimulation these could lead to fruitless repetitive behaviours similar to those seen with stereotypies and compulsions. With certain electrode placements these could persist without satiation. Analogies with obsessive-compulsive disorder and addictive behaviour seemed obvious. Delgado's ${ }^{12}$ work was particularly impressive in demonstrating the close interaction between intracerebral and social-environmental factors in governing behaviour. Radiostimulation of discrete areas of the brain in monkeys could lead to aggressive threatening displays, but only in certain contexts-namely, when the animal was in an appropriate hierarchical relationship to its immediate peers. Here, then, was work in the laboratory which mimicked the sophistication of psychiatry.

Throughout all this, neuropsychology grew in stature, increasing its yield of relevant information. The study of brain damaged patients was adding to knowledge, not only of cognitive processes, narrowly defined, but of such matters as the neural substrates of emotion and of body image disturbances. The immense importance of the prefrontal cortex in relation to key aspects of social functioning became increasingly clear.

In the 1950 s and 1960 s, with an abruptness that could scarcely have been predicted, we saw the upsurge of psychopharmacology. What was striking was the undoubted efficacy of drugs, not in the organic psychiatric domain but in relation to the socalled "functional" psychiatric disorders. This was immensely impressive, both to neurologists and psychiatrists. Medications could alleviate depression, calm mania, even abolish the hallucinations of schizophrenia. These disorders, too, must surely have a cerebral basis.

With this there developed a joint and escalating interest, by neurologists and psychiatrists alike, in the fundamentals of brain biochemistry. During the past three decades there has been an explosive advance in understanding how the brain works at the cellular level. Here is the long awaited justification for Haslam, Griesinger, and others who maintained that the brain was central to mental disorder after all.

As a final strand woven into the tapestry we come to brain imaging. This has been a 
golden thread indeed. With the stage well set, it was natural that this new window into brain abnormality should be vigorously applied to mental disorder. As we shall see such ventures have been rewarding. But they can easily run into trouble without a firm backing from neuropathology. For psychiatry as well as for neurology, neuropathology is the final arbiter, the definitive yardstick, against which new discoveries need to be compared.

\section{The present scene}

So much for history and matters that have come to shape the present day scene. We can turn now to aspects of current progress which illustrate the benefits of a close, continuing relationship between psychiatry and neuropathology. Three common psychiatric conditions will be considered-disorders which absorb an immense share of the facilities, finances, and energies available-dementia, alcoholism, and schizophrenia. In all three neuropathology is steadily refining, sometimes redefining our understanding at a fundamental level.

\section{The dementias}

The principal forms of dementia were described at the turn of the century. But this did not mean that they were properly understood.

The commonest form-Alzheimer's disease-was characterised by plaques and tangles, obvious on histology. It became clear that this was a unitary disease whether affecting the middle aged or elderly. But it remained uncertain how far such features accounted for the mental failure. Could their role be subsidiary, even epiphenomenal, to the core disease process? Plaques could, after all, be found in considerable numbers in mentally well preserved elderly people who had died from other causes.

Psychiatrists, with their aptitude for alternative explanations, sometimes wondered whether the symptoms of dementia might depend, not directly on the brain pathology, but on the nature of the patient's "reaction" to the ageing processes within his brain. ${ }^{13}$ It is not difficult to see how far this line of argument might have been destined to run. But neuropathological studies were to get the matter back on course. Corsellis at Runwell ${ }^{14}$ and Tomlinson, Roth, and Blessed in Newcastle ${ }^{15-18}$ were able to show that the severity of the pathological changes was indeed related to the severity of the clinical picture. Wilcock and Esiri in Oxford showed this very clearly indeed where neurofibrillary tangles were concerned. ${ }^{19}$ Moreover tangle counts correlated with the severity of choline acetyl transferase reductions in the brain. ${ }^{20}$ This has led to an intensive study of the composition and genesis of the tangles themselves, with the finding that they consist of microtubule derived tau protein in altered conformation. ${ }^{2122}$

And of course this is far from the end of the story. New findings are emerging in relation to vascular disturbance and changes in white matter in Alzheimer's dementia. Indeed its distinction from vascular dementia is under reappraisal once again. This story begins with brain imaging, when it was found that some demented patients showed low attenuation in the white matter, especially in the periventricular regions. ${ }^{23-25}$ At first this was thought to be rare, perhaps a reflection of Binswanger's disease-a rather esoteric variant of vascular dementia. But as scanning techniques improved the incidence steadily rose. It was rechristened "leukoaraiosis", 26 and found in up to a third of patients with Alzheimer's disease. ${ }^{27}$ Ivan Janota had already drawn attention to changes in white matter at necropsy in certain patients who seemed to have Alzheimer's disease. ${ }^{28}$ And Brun and Englund have now reported them in well over half. ${ }^{29}$ When present the changes show distinct associations with vascular risk factors, ${ }^{30}$ and are thought to reflect hypoperfusion in the territories involved. Amyloid deposition in blood vessels could be aetiologically relevant.

Thus the situation regarding white matter lucency in dementia has altered considerably, from a suspected marker of Binswanger's disease, through something that is seen in most multi-infarct dementias, to something affecting a substantial proportion of patients with Alzheimer's disease. It seems as though vascular factors and Alzheimer changes may commonly reinforce one another. The traditional distinction between parenchymatous and vascular dementia is becoming to some extent blurred, and another view of the pathogenesis of Alzheimer's dementia may be opening up.

Next we come to the frontal lobe dementias. Independently of one another, Brun ${ }^{31}$ and Gustafson ${ }^{32}$ in Sweden, and Neary et al in Manchester, ${ }^{33}$ have drawn attention to a sizeable group of patients whose dementia presents with social breakdown rather than overt cognitive failure. These are of great importance to psychiatry. Such patients are not infrequently misdiagnosed for some considerable time-as hypomania, alcoholism, or personality disorder. Some have presented as obsessional disorder, even responding at first to treatment for this. The importance of the group lies in its frequency and in the challenge it presents for neuropathology. It has been estimated to account for up to $10 \%$ of cases of dementia, ${ }^{34}$ especially those setting in in the presenile period. There is also a distinct familial incidence.

And what of the neuropathological basis? Some cases seem to represent classical Pick's disease, but, and this is the important discovery, the great majority do not. Some $80 \%$ of them lack all evidence of Pick's or of Alzheimer's pathology. ${ }^{34}$ They show frontotemporal degenerative changes of an ill defined nature, with mild loss of neurons, and slight gliosis and spongiosis. Very occasionally the same clinical picture, and the histology, is seen in patients with amyotrophic 
lateral sclerosis. ${ }^{35}$ Altogether the neuropathological relationships within the group of frontal dementias remain confused. Their clarification will be a necessary prelude to attempts at understanding aetiology.

Finally with the dementias we must consider Lewy body disease. This has appeared rather suddenly on the scene in recent years. ${ }^{3641}$ The Lewy body is the hallmark of Parkinson's disease, appearing in the pigmented substantia nigra and other brain stem nuclei. But it is now apparent that it may also be found in considerable numbers in the cerebral cortex-socalled "diffuse Lewy body disease"-and that this is associated with dementia. Most affected patients show both dementia and parkinsonian features, but some seem to show dementia alone. The dementia is cortical in type, often fluctuates, and tends to be accompanied by hallucinations and behavioural disturbance. It is not infrequently diagnosed during life as multiinfarct dementia. This recent discovery is of the utmost importance. It could account for the dementia encountered in a proportion of patients with Parkinson's disease (up to $30 \%$ ). It could help to explain the high incidence of extrapyramidal features in Alzheimer's disease (up to $50 \%$ ). And it could account in part for the repeated finding that some elderly demented patients lack easily visible pathology (some $10 \%$ ). The Lewy body is hard to detect in the cortex with routine stains, and much of the recent work has made use of immunocytochemistry. Antiubiquitin antibodies provide a sensitive means for the detection of Lewy bodies. ${ }^{42}$ The current suggestion is that Lewy body dementia may yet prove to be second only to Alzheimer's disease as a cause of dementia in the elderly. ${ }^{38} 39$ If so we have been labouring too long with a severely restricted view.

This is one of the fascinations of neuropathology, that the more closely you look the more you may find. One gets the feeling at times of looking for needles in a haystack, but when they are found they can revolutionise our conceptions.

\section{Alcoholic brain damage}

Korsakoff is rightly famous for his description of the amnesic syndrome that bears his name. But it has emerged that that is not the end of the story concerning brain damage in alcoholism. It now seems that many chronic alcoholics, without this striking complication, also harbour brain damage of a more subtle nature.

The concept of alcoholic dementia fell steadily out of favour when the distinctive pathology of the Wernicke-Korsakoff syndrome was elucidated, and it became a matter of controversy whether the cerebral cortex was liable to suffer. Alcoholics were said to be prey to an "addictive process", of an ill defined nature, which led to their notorious inability to benefit from attempts at treatment. Coupled to this was the idea of "preexisting personality difficulties" which were fundamental to the addictive process and served to perpetuate it. The alcoholic's facile, garrulous, and unreliable behaviour was often held to reflect such personality defects.

But a careful reappraisal now suggests that a proportion of severe alcoholics may eventually become victims of a circular process, whereby cerebral changes induced by their heavy consumption and its attendant risks weaken their capacity to abstain. And this proportion may be quite substantial. ${ }^{43}$ The refocusing of interest on the cortex came largely from neuropsychological studies and from brain imaging. Soon after computerised tomography became available, it was shown that brain "shrinkage" was apparent in a half to two thirds of cases. In comparison with controls, the ventricles of alcoholics were enlarged by some $50 \%$, and widening of the fissures and sulci was often detectable. Such findings emerged from many centres. ${ }^{44-46}$ With abstinence there could be a gradual return towards normality on the scans, but this was a slow process and often incomplete..$^{45} 46$ Even many years later, persisting cerebral changes could be demonstrated among Alcoholics Anonymous members who had abstained for a decade or more. ${ }^{47}$ The nature of this shrinkage and its pathogenesis has remained uncertain; also the processes that may permit its partial reversal. But neuropathological studies are bringing a degree of clarity. Professor Clive Harper and his colleagues in Australia have made a series of elegant studies, using quantitative methods to help settle the matter of cortical involvement. On gross morphology they have found brain weight to be slightly but significantly reduced, and the pericerebral space over the hemispheres to be increased. ${ }^{48}{ }^{49}$ This is seen independently of the presence or absence of nutritional brain damage. The percentage of white matter is reduced, and the enlargement of the ventricles (by a mean of $50 \%$ ) confirmed..$^{50}$

A start has been made on neuronal counts in the cerebral cortex. Although such data are sparse at present there are firm indications of a reduced neuronal population, at least in the superior frontal cortex. ${ }^{51}$ Total counts were normal elsewhere, but there was shrinkage of neurons in the cingulate and motor cortex as well. The 22 alcoholics involved included some with Wernicke's encephalopathy and some with liver cirrhosis. But almost half of them had neither, and these showed equivalent reductions.

Harper and Corbett have further attempted an assessment of dendritic arborisations in a small group of alcoholics and controls. ${ }^{52}$ The alcoholics showed reductions in mean dendritic length, number of branches, and width of basal dendritic fields, as measured in layer III pyramidal neurons of the superior frontal cortex. This last observation is interesting in view of certain experimental findings. McMullen et al in Toronto ${ }^{3}$ have shown that after five months of exposure to alcohol in the rat, dendritic domains are reduced in extent in the hippocampus, with reduction in thick- 
ness of the corresponding dendritic strata. Two months of abstinence allows regrowth of dendritic branching and a return to normal thickness of the strata. This experimental work provides a tempting analogy with what is observed on brain imaging in the human alcoholic. There is evidence that dendritic arbors normally expand continuously throughout adult life, presumably in compensation for the decline in neuronal numbers over the years. ${ }^{54}$ In the alcoholic this delicate compensatory balance may be imperilled.

It is clear from all studies that not all alcoholics are equivalently at risk of cerebral involvement. Such variability appears not to depend on patterns of drinking, or to be explained entirely by the coincident risks of cerebral anoxia, hypoglycaemia, malnutrition, or head injury. These matters are hard to evaluate with precision, but it seems likely that individual susceptibility, perhaps on a genetic basis, is also very important. And as with the liver, females appear to be at increased risk. ${ }^{55}$ Thus some alcoholics may be especially vulnerable to cerebral changes induced by alcohol consumption, even though they escape the development of a Korsakoff syndrome. The alcoholic patient illustrates very well the need for continuing liaison between neuropathology and psychiatry.

\section{Schizophrenia}

And last we come to schizophrenia, perhaps the most baffling of all psychiatric disorders with respect to aetiology. An organic basis has been suspected since Kraepelin's time but has remained remarkably elusive. And there have been radically different ideas concerning aetiology. Schizophrenia has been seen as the outcome of faulty psychological development, aided and abetted by faulty parental rearing. The schizophrenogenic mother and the pathogenic family have had their vogue. Social processes, particularly within institutions, have been blamed for the "schizophrenic defect state".

The development of theories which bypassed all reference to the brain is not hard to understand. It followed in the wake of long and detailed research which failed to clarify a neuropathological basis for the disorder. The Vogts $^{56}$ spent a lifetime examining the brain with results that failed to gain wide acceptance. In 1972 Plum $^{57}$ made the peculiarly compelling remark that "schizophrenia is the graveyard of neuropathologists". Moreover any attempt at an organic model met with very particular difficulties in that the strange phenomena of schizophrenia did not mirror the effects of known brain lesions; neurology was hard pressed to encompass its bizarre manifestations.

But the last decade or so has seen an upsurge of interest once again. This of course is tempered with caution. We have lived through too many false hopes to react with anything else. In particular we know that narrowly conceived models of cause and effect are unlikely to be upheld.
What clues do we have to guide us? Certain observations are firm-genetic liability, a tendency to appear in adolescence or early adult life, response to certain medications, and distinct associations in some cases with pathology in the temporal lobes and limbic areas. This tendency to arise with regional brain pathology perhaps tells neuropathologists where to look most closely. Other findings are almost as firm and need to be taken into account - season of birth effects, vulnerability to life events and to "expressed emotion" within the family, the presence of antecedent impairments from childhood onwards, and a host of tantalising relationships with aspects of cerebral laterality.

So neuropathologists have been encouraged to look at the brain anew. Bogerts and coworkers $^{58}$ have reexamined the Vogts' collection of brains, gathered before the era of neuroleptics and insulin treatment, and showed reductions in size of the globus pallidus and several limbic structures. Shrinkage of the hippocampal formation was sometimes obvious macroscopically. Corsellis's group ${ }^{59}$ measured a larger sample from Runwell, showing pronounced enlargement of the temporal horns and thinning of the parahippocampal cortex (particularly on the left) in comparison with patients with affective disorder. Crow et $a l^{60}$ have shown enlargement largely restricted to the left temporal hornsthat is, to that part of the brain in which anatomical asymmetries are normally present. In all of these studies gliosis was conspicuous by its absence, suggesting a developmental disturbance rather than the end result of early damage to the brain.

Scheibel and coworkers ${ }^{61}{ }^{62}$ have focused on the hippocampus, claiming alterations in pyramidal cell orientation from orderly to disorderly alignments, with corresponding disorganisation of their dendritic arrays. In some parts of the hippocampus the proportion of cells rotated by 30 degrees or more was increased sevenfold or eightfold in comparison with controls. The extent of the effect seemed to be related to the severity of the clinical picture. They suggest that this may represent the product of disturbed migration of neurons into the primordial hippocampus during the second trimester of pregnancy. The migration and alignment of nerve cells is governed by "neuronal cell adhesion molecules", and it is suggested that these could be vulnerable to maternal infection with neuraminidase bearing viruses, perhaps aided by inherited defects in immunocompetence.

Recent results from the studies of Akbarian and coworkers ${ }^{6364}$ are also fascinating. They have used histochemistry to identify a particular population of neurons in the grey matter and subjacent white matter (NADPH-d neurons). Having migrated towards the cortex during fetal development these are normally found in greatest numbers immediately deep to layer VI of the cortex. In schizophrenic brains, however, their distribution is shifted significantly inwards and they are found in deeper layers of the white matter. This is fur- 
ther evidence of disturbed migration during neural development. The findings of Akbarian et al apply to the medial and the lateral temporal lobe structures, and also to the dorsolateral prefrontal cortex, which has been shown by neuroimaging techniques to be dysfunctional in schizophrenia. It would seem unlikely that these cytoarchitectonic abnormalities could have arisen other than through some failure of cerebral development. It is important to note that insights at this level have become available only through the medium of neuropathology. Also that they are generated by a synthesis of clinical and neuroscientific information - that is, by ongoing dialogue between psychiatrists and neuropathologists.

As ever, however, the mysteries of schizophrenia continue to keep one step ahead. This plethora of studies has focused principally on the temporal lobe regions, and for very good reasons. But who knows what may be waiting to be discovered elsewhere? As other parts of the brain come under scrutiny it seems that they, too, may be affected. Zipursky and coworkers, ${ }^{65}$ for example, have recently made a detailed volumetric study of multiple brain regions, using magnetic resonance imaging (MRI). They find grey matter reductions, not restricted to the temporal lobes, but diffusely throughout most parts of the cerebral cortex. Harvey, Ron, et $a l^{66}$ working at the Institutes of Neurology and Psychiatry, have confirmed such findings, showing, moreover, that they are specific to schizophrenia, at least in that they are not found in manic-depressive psychosis. ${ }^{67}$ These MRI findings were mirrored in an earlier postmortem investigation by Pakkenberg, ${ }^{68}$ who demonstrated widespread reductions of both cortical and subcortical grey matter in schizophrenic patients. So it seems possible that the cortex is diffusely affected in schizophrenia, in addition to any selective emphasis on particular brain regions. This could go some way towards explaining the pleomorphic features of the disease, and perhaps its variability of expression in different patients.

Be that as it may, an accumulation of evidence now points to the "neurodevelopmental theory of schizophrenia". ${ }^{69-71}$ It has been possible to sketch in only a part of the indicators in this direction. It is suggested that many schizophrenics harbour brain lesions which have originated very early in life, extending back even to the intrauterine period. Such lesions predispose the person to develop schizophrenia later. They are of a subtle nature and were easily missed by earlier pathologists. The anomalies concerned may be the product of infection, perinatal trauma, or, the now favoured theory, patterns of abnormal neural migration. This last may be occasioned by maternal infection during pregnancy, or may itself be inherited directly. These lesions declare themselves fully only 15-20 years later, because they need to interact with normal brain maturational processes before their impact is revealed. This is the distinctive aspect of the "schizophrenic brain lesion"-that it involves systems that have yet to mature functionally. Putting it another way, the lesion remains largely dormant until further brain maturation calls the damaged neuronal systems into operation. A good deal of theorising centres on this aspect of the situation. ${ }^{6972}$ It may be that the immature circuitry is laid bare by synaptic pruning, a process which in some brain areas continues into late adolescence. Or it may depend on the maturing of cortical-subcortical relationships. The dorsolateral prefrontal cortex, for example, is one of the last brain areas to myelinate, this continuing into the second and third decades of life. In animals lesions in such a location can disturb the relationship between cortical and subcortical dopamine metabolism. This could be very relevant. Adolescence is notably a time of stress, and stress could tax a faulty system.

Thus with some ingenuity the neurodevelopmental model can be made to encompass many aspects of what we know about schizophrenia. But caution is strongly indicated. There is still plenty of room for debate.

\section{Conclusion}

In conclusion, these examples amply confirm the value of a continuing relationship between psychiatry and neuropathology. It is in the nature of relationships that they can be stormy, and that as they mature they pass through various stages. In the early 19th century the relationship between psychiatry and neuropathology tended to be one of blind faith. By the middle of the century this had changed to obsession and was provoking alarm. Towards the end the focused activity had repaid dividends, in the delineation of the major dementing illnesses, but the situation for psychiatry generally was becoming embroiled in doubt and conflict.

As we entered the 20th century psychiatry was finding other avenues and more immediate rewards by studying the development of the mind and analysing the minutiae of the patient's interactions with his world. But the second part of the 20th century has seen a pronounced maturing of the relationship, and such maturing has had several elements. Mature relationships will permit areas of doubt and tolerate competing points of view. They can stand back and evaluate matters by objective and realistic means. They involve a capacity to share, and appreciate the need to join forces in unravelling problems. And as I see it maturing of this nature has taken place in both psychiatry and in neuropathology.

Psychiatry has learned to be less possessive about its unique avenues and insights into mental disorder. As well as studying psychosocial forces it can prosper, like neurology, by studying the brain. It has learned to be less jealous of neurology's allegiance with neuropathology, but to join forces in this alliance. It has been able to change its orientations where certain disorders are concerned, notably schizophrenia. 
Neuropathology has also matured. It has become less distrustful towards psychiatry, more tolerant of its peculiar difficulties, less daunted by its complexities. It has diversified by embracing histochemical, immunocytological, and detailed quantitative techniques. It now takes a lively interest in psychiatric problems, and has learned the value of this additional outlet to its endeavours.

David Oppenheimer was a tolerant and enthusiastic scientist. He would certainly have been eager to share fully in the challenges and interests that now surround us and that certainly lie ahead.

I am grateful to Professor Maria Ron for reading a draft of the lecture and for helpful suggestions.

1 Bacon F. The twoo bookes. ... Of the proficience and advancement of learning, divine and humane. London, Tomes Book 2, folios 35-8, 41-2, 77(84)-74(85), 1605. Quoted by Hunter R, MacAlpine I. Three hundred years of psychiatry, 1535-1860. London: Oxford ersity Press, 1963

2 Abercrombie J. Pathological and practical researches on diseases of the brain and the spinal cord. Edinburgh. 1828. Quoted by Hunter R, Macalpine I. Three hundred years of Psychiatry: 1586-1860 London: Oxford University Press, 1963.

3 Griesinger W. Quoted by Zilboorg G, Henry GW. $A$ history of medical psychology. London: Allen and Unwin, $1941 ; 436$. 4 Heinroth J. Quoted by Zilboorg G, Henry GW. A history
of medical psychology. London: Allen and Unwin, 1941; 470 .

5 Noguchi H, Moore JW. A demonstration of treponema pallidum in the brain in cases of general paralysis. $f$ Exp Med 1913;17:232-8.

6 von Economo C. Encephalitis lethargica: its sequelae and treatment. London: Oxford University Press. First published 1929. Translated by Newman KO, 1931.

7 Bard P. A diencephalic mechanism for the expression of rage with special reference to the sympathetic nervous system. Am F Physiol 1928;84:490-515.

8 Kluver $\mathrm{H}$, Bucy PC. Preliminary analysis of functions of the temporal lobes in monkeys. Archives of Neurology and Psychiatry 1939;42:979-1000.

9 Ward AA. The cingular gyrus: area 24. I Neurophysiol 1948;11:13-22.

10 Glees P, Cole J, Whitty CWM, Cairns N. The effects of lesions in the cingular gyrus and adjacent areas in monkeys. F Neurol Neurosurg Psychiatry 1950;13:178-90.

11 Olds J, Milner P. Positive reinforcement produced by electrical stimulation of septal area and other regions of rat brain. Fournal of Comparative Physiology and rat brain. fournal of Com $1954 ; 47: 419-27$.

12 Delgado JMR. Aggression and defence under cerebral radio control. In: Clemente $C D$, Lindsley $D$, eds. Agression and defense, neural mechanisms and social patAggression and defense, neural mechanisms and social pat-
terns. UCLA forum in Medical Science. No 7, Vol V. terns. UCLA forum in Medical Science. No 7, Vol

13 Rothschild D. Senile psychoses and psychoses with cerebral arteriosclerosis. In: Kaplan OJ, ed. Mental disorders in later life. Stanford, USA: Stanford University Press, 1956.

14 Corsellis JAN. Mental illness and the ageing brain. Maudsley Monograph No 9. London: Oxford University Press, 1962.

15 Roth M, Tomlinson BE, Blessed G. The relationship between quantitative measures of dementia and of degenerative changes in the cerebral grey matter of elderly subjects. Proceedings of the Royal Society of Medicine 1967;60:254-9.

16 Tomlinson BE, Blessed, G, Roth M. Observations on the brains of non-demented old people. $f$ Neurol $S_{c i}$ $1968 ; 11: 331-56$

17 Blessed G, Tomlinson BE, Roth $M$. The association between quantitative measures of dementia and of senile change in the cerebral grey matter of elderly subjects. $\mathrm{Br}$ f Psychiatry 1968;114:797-811.

18 Tomlinson BE, Blessed, G, Roth $M$. Observations on the brains of demented old people. $\mathcal{f}$ Neurol Sci 1970;11: 205-42.

19 Wilcock GK, Esiri MM. Plaques, tangles, and dementia: a quantitative study. F Neurol Sci 1982;56:343-56.

20 Wilcock GK, Esiri MM, Bowen DM, Smith CCT. Alzheimer's disease. Correlations of cortical choline acetyl-transferase activity with the severity of dementia
and histological abnormalities. F Neurol $S c i$ 1982;57: 407-17.

21 Wischik CM, Novak M, Thogersen HC, et al. Isolation of a fragment of tau derived from the core of the paired helical filament of Alzheimer disease. Proc Natl Acad Sci helical filament of

22 Wischik CM, Novak M, Edwards PC, Klug A, Tichelaar
W, Crowther RA. Structural characterisation of the core of the paired helical filament of Alzheimer disease. Proc Natl Acad Sci 1988;85:4884-8.

23 Valentine AR, Moseley IF, Kendall BE. White matter abnormality in cerebral atrophy: clinico-radiological correlations. $\mathcal{f}$ Neurol Neurosurg Psychiatry 1980;43: correlation.

24 Goto K, Ishii N, Fukasawa H. Diffuse white matter disease in the geriatric population. Radiology 1981;141 687-95.

25 George AE, de Leon MJ, Gentes CI, et al. Leukoencephalopathy in normal and pathologic aging. $A \mathcal{F N R}$ Am $\mathscr{f}$ Neuroradiology 1986;7:561-6.

26 Hachinski VC, Potter P, Merskey H. Leuko-araiosis. Arch Neurol 1987;44:21-3.

27 Steingart A, Hachinski VC, Lau C, et al. Cognitive and neurologic findings in demented patients with diffuse white matter lucencies on computed tomographic scan (leuko-araiosis). Arch Neurol 1987;44:36-9.

28 Janota I. Dementia, deep white matter damage and hypertension: "Binswanger's disease". Psychol Med 1981;11: 39-48.

29 Brun A, Englund E. A white matter disorder in dementia of the Alzheimer type: a pathoanatomical study. Ann Neurol 1986;19:253-262.

30 Inzitari D, Diaz F, Fox A, et al. Vascular risk factors and leuko-araiosis. Arch Neurol 1987;44:42-7.

31 Brun A. Frontal lobe degeneration of non-Alzheimer type. I Neuropathology. Archives of Gerontology and Geriatrics 1987;6:193-208.

32 Gustafson L. Frontal lobe degeneration of non-Alzheimer type. II Clinical picture and differential diagnosis. Archives of Gerontology and Geriatrics 1987;6:209-23.

33 Neary D, Snowden JS, Northen B, Goulding P. Dementia of frontal lobe type. $\mathcal{F}$ Neurol Neurosurg Psychiatry of frontal lobe

34 Gustafson L, Brun A, Passant U. Frontal lobe degeneration of non-Alzheimer type. In: Rossor MN, ed.
Balliere's clinical neurology. International practice and Balliere's clinical neurology. International practice
research. Unusual dementias 1992;1, No 3:559-82.

$35 \mathrm{Kew}$ J, Leigh N. Dementia with motor neurone disease. In: Rossor MN, ed. Ballière's clinical neurology. International practice and research. Unusual dementias 1992;1, No 3:611-26.

36 Gibb WRC, Esiri MM, Lees AJ. Clinical and pathological features of diffuse cortical Lewy body disease (Lewy body dementia). Brain 1987;110:1131-53.

37 Gibb WRG, Luthert PL, Janota I, Lantos PL. Cortical Lewy body dementia: clinical features and classification. f Neurol Neurosurg Psychiatry 1989;52:185-92.

38 Byrne EJ, Lennox G, Lowe J, et al. Diffuse Lewy body disease: clinical features in 15 cases. $\mathcal{f}$ Neurol Neurosurg Psychiatry 1989;52:709-717.

39 Perry RH, Irving D, Blessed G, et al. Senile dementia of Lewy body type. F Neurol Sci 1990;95:119-39.

40 Hansen L, Salman D, Galasko D, et al. The Lewy body variant of Alzheimer's disease: a clinical and pathologic entity. Neurology 1990;40:1-8.

41 McKeith IG, Perry RH, Fairbairn AF, Jabeen S, Perry EK. Operational criteria for senile dementia of Lewy body type (SDLT). Psychol Med 1992;22:911-22.

42 Lennox G, Lowe J, Morrell K, Landon M, Mayer RJ. Anti-ubiquitin immunocytochemistry is more sensitive than conventional techniques in the detection of diffuse Lewy body disease. $\mathcal{F}$ Neurol Neurosurg Psychiatry 1989 52:67-71.

43 Lishman WA. Alcohol and the brain. Br f Psychiatry 1990;156:635-44.

44 Bergman H, Borg S, Hindmarsh $\mathrm{T}$, et al. Computed tomography of the brain and neuropsychological assessment of male alcoholic patients and a random sample from the general male population. Acta Psychiatr Scand from the general male pop

45 Carlen PL, Wilkinson DA. Alcoholic brain damage and reversible deficits. Acta Psychiatr Scand 1980;62(suppl reversible defici

46 Ron MA, Acker W, Shaw GK, et al. Computerised tomography of the brain in chronic alcoholism. A survey and follow-up study. Brain 1982;105:497-514.

47 Lishman WA, Jacobson RR, Acker C. Brain damage in alcoholism: current concepts. Acta Medica Scandinavica 1987;suppl 717:5-17.

48 Harper C, Blumbergs PC. Brain weights in alcoholics. $f$ Neurol Neurosurg Psychiatry 1982;45:838-40

49 Harper C, Kril J. Brain atrophy in chronic alcoholic patients: a quantitative pathological study. $\mathcal{f}$ Neurol Neurosurg Psychiatry 1985;48:211-17.

50 Harper C, Kril J, Holloway RL. Brain shrinkage in chronic alcoholis: a pathological study. $B M F 1985 ; 290$ : 501-4.

51 Harper C, Kril J, Daly J. Are we drinking our neurones away? $B M F$ 1987;294:534-6.

52 Harper $C$, Corbett D. Changes in the basal dendrites of cortical pyramidal cells from alcoholic patients-a quantitative Golgi study. $\mathcal{J}$ Neurol Neurosurg Psychiatry 1990;53:856-61.

53 McMullen PA, Saint-Cyr JA, Carlen PL. Morphological alterations in rat CA1 hippocampal pyramid cell dendrites resulting from chronic ethanol consumption and drites resulting from chronic ethanol consum

54 Buell SJ, Coleman PD. Dendritic growth in the aged human brain and failure of growth in senile dementia. human brain and failure

55 Jacobson RR. The contributions of sex and drinking history to the CT brain scan changes in alcoholics. Psychol Med 1986;16:547-59. 
56 Vogt C, Vogt O. Altérations anatomiques de la schizophrénie et d'autres psychoses dites fonctionelles First International Congress of Neuropathology 1952;1: 515-32.

57 Plum F. Prospects for research on schizophrenia. 3. Neuropsychology. Neuropathological findings. Neurosciences Research Program Bulletin 1972;10:384-8.

58 Bogerts B, Meertz E, Schonfeldt-Bausch R. Basal ganglia and limbic system pathology in schizophrenia. A morphometric study of brain volume and shrinkage. Arch phometric study of brain volume

59 Brown R, Colter N, Corsellis JA, et al. Postmortem evidence of structural brain changes in schizophrenia Differences in brain weight, temporal horn area, and parahippocampal gyrus compared with affective disorder. Arch Gen Psychiatry 1986;43:36-42.

60 Crow TJ, Ball J, Bloom SR, et al. Schizophrenia as an anomaly of development of cerebral asymmetry. Arch Gen Psychiatry 1989;46:1145-50.

61 Kovelman JA, Scheibel AB. A neurohistological correlate of schizophrenia. Biol Psychiatry 1984;19:1601-21.

62 Conrad AJ, Scheibel AB. Schizophrenia and the hippocampus: the embryological hypothesis extended. Schizophr Bull 1987;13:577-87.

63 Akbarian S, Bunney WE, Potkin SG, et al. Altered distribution of nicotinamide-adenine dinucleotide phosphate-
diaphorase cells in frontal lobe of schizophrenics implies diaphorase cells in frontal lobe of schizophrenics implies disturbances of cortical
Psychiatry 1993:50:169-77.

64 Akbarian S, Viñuela A, Kim JJ, Potkin SG, Bunney WE, Jones EG. Distorted distribution of nicotinamide-ade- nine dinucleotide phosphate-diaphorase neurons in temporal lobe of schizophrenics implies anomalous cortical development. Arch Gen Psychiatry 1993;50: 178-87.

65 Zipursky RB, Lim KO, Sullivan EV, Brown BW, Pfefferbaum A. Widespread cerebral grey matter volume deficits in schizophrenia. Arch Gen Psychiatry 1992;49: deficits in 205.

66 Harvey I, Ron MA, du Boulay G, Wicks D, Lewis SW, Murray RM. Reduction of cortical volume in schizophrenia on magnetic resonance imaging. Psychol Med 1993;23:591-604.

67 Harvey I, Persuad R, Ron MA, Barker G, Murray RM. Volumetric MRI measurements in bipolars compared with schizophrenics and healthy controls. Psychol Med 1994;24:689-99.

68 Pakkenberg B. Post-mortem study of chronic schizophrenic brains. Br f Psychiatry 1987;151:744-52.

69 Weinberger DR. Implications of normal brain development for the pathogenesis of schizophrenia. Arch Gen Psychiatry 1987;44:660-9.

70 Murray RM, Lewis SW, Owen MJ, Foerster A. The neurodevelopmental origins of dementia praecox. In: Bebbington P, McGuffin P, eds. Schizophrenia: the major issues. Oxford: Heinemann, 1988; Ch 8 .

71 Heyman I, Murray RM. Schizophrenia and neurodevelopment. Fournal of the Royal College of Physicians of London 1992;26:143-6.

72 Murray RM. Neurodevelopmental schizophrenia: the rediscovery of dementia praecox. $\mathrm{Br} \mathcal{F}$ Psychiatry 1995(in press).

\section{Thomas Sydenham "The British Hippocrates"}

Details of Sydenham's life are few. The Sydenhams, an ancient family were in the time of King John, seated at Sydenham near Bridgewater. Thomas was son of Mary Geffery of Catherstone and William Sydenham. Little is known of his childhood. In 1642 he was entered at Magdalen Hall, Oxford, and left shortly after for military service as a Parliamentarian. He probably returned to Magdalen Hall in 1646, advised by Dr Thomas Coxe (PRCP, 1682) to read medicine, taking the degree of $\mathrm{MB}$ in April 1648. He was made a Fellow of All Souls, but went to Wadham as a commoner. He moved to Westminster, before 1661 when his earliest account of epidemics of London were written. On 25 June 1663 he was admitted Licentiate of the College of Physicians.

In 1666 was published the first edition of Methodus Curandi Febres, propriis observationibus superstructa, in the Philosophical Transactions, which became Transactions of the Royal Society, in four sections: continued fevers, the symptoms of continued fevers, intermittent fever, smallpox. The dedication includes a tribute to Robert Boyle. A second edition in 1668 included a chapter on the plague, which was epidemic in London in 1645 and 1646. It contains Latin elegiacs revering Dr John Locke, the "founder of analytical philosophy of the mind".' The third edition (1676) bore the new title Observationes Medicae, and was dedicated to Dr Mapletoft and included copious new material. Sydenham took the degree of Doctor of Medicine, not at Oxford, but at Cambridge (May 17 1676), possibly because his son was two years earlier admitted a pensioner at Pembroke College.

For three months in 1677 he was laid low by haematuria and gout, an affliction he first suffered in 1649. Then followed a series of Epistola Responsaria and Dissertatio
Epistolaris describing smallpox, venereal disease, hysteria, and podagra (gout), and the celebrated Tractatus de Podagra et Hydrope, London 1683. These works were published in Britain, Geneva, and in Amsterdam.

There is an anecdote about him, cursorily dismissed by Munk as "utterly valueless": when asked why he did not write about diseases of the head, he answered that he did not undertake to write upon diseases that he was unable to cure. Times don't change. Referring to his failure to become a Fellow of the Royal College, Lettsom wrote in 1804: "The great Sydenham, for all his labours, only gained the sad and unjust recompense of calumny and ignorance ....". However, Munk ${ }^{2}$ relates that ". . . he did not proceed doctor (MD) till after a lapse of twenty eight years ... he was content with the minor degree and, as such, was, by the statutes . . . inadmissible as a Candidate, and a fortiori, as a Fellow . . . examination of the Annals enables me positively to assert that he never sought admission to the fellowship."

Sydenham had a powerful influence on contemporary medicine. Diligent and scientific in his methods, observation and pragmatism were his hallmarks. He saw himself as the servant of God and nature.

In 1689 still in practice, he was ill with renal stone, haematuria, and gout. He died at home in Pall Mall on 29 December 1689 and was buried in the church of St James's, Westminster.

304 Beverley Road

J M S PEARCE Anlaby

Hull HUIO $7 B G, U K$

1 Brown J. Locke and Sydenham and other papers. Edinburgh: David Douglas, 1882:33-135.

2 Munk W. The Roll of the Royal College of Physicians of London. 2nd ed, vol 1, 1518 to 1700. London: published by the College, Pall Mall East, 1878:309-14.

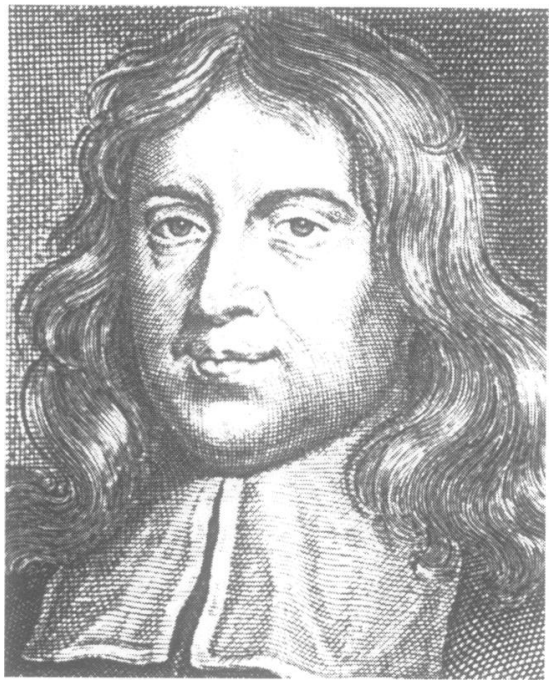

prope hunc locum sepultus est THOMAS SYDENHAM

medicus in omne aevum nobilis natus erat $\mathrm{AD} 1624$ vixit annos 65

deletis veteris monumenti vestigiis, ne rei memoria interiret,

hoc marmor poni jussit collegium regale medicorum londinense $\mathrm{AD} 1810$ optimè merito

nearby is the burial place of

THOMAS SYDENHAM

noble physician of the age Born AD 1624

He lived to 65 years

age erases remnants and monuments, nothing in his memory will perish. This marble is placed by command of the Royal College of Physicians of London AD 1810 in greatest merit

Epitaph to Thomas Sydenham on the tablet erected by the College in 1810 